\title{
Research on constitutive relationships of concrete filled steel tube
}

\author{
X.M. Chen, J. Duan, Y.G. Li \\ China state construction technical center, Beijing, China
}

\begin{abstract}
KEYWORD: Constitutive relationship; Concrete filled steel tube; Elastic-plastic
ABSTRACT: The strength and ductility of concrete will dominate structural performance under expected rare earthquake, and concrete filled steel tube is an effective solution for this goal in super high-rise buildings. As reliable numerical simulation of these kinds of structures may depend on reasonable constitutive relationship, two typical constitutive models are analyzed in this paper, and they are also being compared with the constitutive relationship of plain concrete for equivalent Young' s modulus and the initial stages of skeleton curves. The results show that these two models all can embody the confining effect of steel tube, but they are not suitable for low-stress state and modal analysis.
\end{abstract}

\section{INTRODUCTION}

To ensure the building safety enough for lives, nonlinear time-history analysis is essential for expected rare earthquake. Compared with the structures under small earthquake, nonlinearity of material and geometry may be the key point for rare earthquake. For those high buildings of reinforced concrete, the influence of material nonlinearity is much more significant than geometric nonlinearity, so reasonable material constitutive model is the precondition for reliable results.

Most widely used concrete constitutive relationship includes cracking, smeared cracking and damaged plasticity model. Concrete smeared cracking is designed for applications in which the concrete is subjected to essentially monotonic straining at low confining pressures; Concrete cracking is designed for applications in which the behavior is dominated by tensile cracking, and concrete damaged plasticity is designed for applications in which concrete is subjected to monotonic, cyclic, and/or dynamic loading under low confining pressures. Thus concrete damaged plasticity is widely used for structural analysis under the action of seismic wave.

Usually, concrete is designed being confined with stirrups in frames or confined by rebar layers in shell to improve strength and ductility. In the constitutive model presented in "Code for design of concrete structures" (2011), a confining parameter is available for modifying ultimate strength and ultimate stain. This parameter also can be used to change the shape of skeleton curves.

Although this model is accurate enough for simulating the behavior of most reinforced concrete members, parameter designed for stirrups cannot be used for concrete filled steel tube where concrete is confined much stronger. For excellent ductility under seismic waves, concrete filled steel tube is not only used widely for columns but also has been introduced in shear wall structure by $\operatorname{Ren}(2013)$ as the structural height being higher and higher.

For concrete in steel tube, constitutive relationship of reinforced concrete may overestimate the damage induced by seismic waves because of essential differences of confining effect. Aimed at these differences, researchers developed models for concrete filled steel tube. Some of these models are formulated by developing equivalent skeleton curves of concrete and steel tube, such as $\mathrm{Yu}$ an's(2004) model, and some of the others are formulated via a parameter of confining effect, such as Susanth's model(2001) and Hsuan-The Hu's model(2003). By arranging test data, professor Zhong(2003) and Han(2007) also developed the same kind of constitutive models which are more concise and have been accepted by Chinese engineers.

The models of Zhong and Han are researched in this paper for application. Their differences are shown by curves. By being compared together with the constitutive relationship presented by "Code 
for design of concrete structures", deficiencies of these two models are also researched for the concrete under low stress state.

\section{CONSTITUTIVE MODEL OF "CODE FOR DESIGN OF CONCRETE STRUCTURES"}

The constitutive model presented in Chinese 'Code for design of concrete structures' called Code's model was developed for plain concrete, in which the compression skeleton curve of concrete is as follows:

$$
\begin{gathered}
\sigma=\left(1-d_{c}\right) E_{c} \varepsilon \\
d_{c}= \begin{cases}1-\frac{\rho_{c} n}{n-1+x^{n}} & x \leq 1 \\
1-\frac{\rho_{c}}{\alpha_{c}(x-1)^{2}+x} & x>1\end{cases}
\end{gathered}
$$

where

$$
\begin{aligned}
& \rho_{c}=\frac{f_{c, r}}{E_{c} \varepsilon_{c, r}} \\
& n=\frac{E_{c} \varepsilon_{c, r}}{E_{c} \varepsilon_{c, r}-f_{c, r}} \\
& x=\frac{\varepsilon}{\varepsilon_{c, r}}
\end{aligned}
$$

and

$f_{c, r}$ is the compression strength

$\varepsilon_{c, r}$ is the peak compression strain

$\alpha_{c}$ is the shape parameter

In this formulation, concrete can keep linear elastic when damage of compression is 0 , thus it still can lead to much more acceptable results in nonlinear analysis even in the state of low stress.

\section{Model of Shantong Zhong}

Based on analysis on more than 50 groups of axial compression results for concrete columns filled steel tube, professor Zhong developed his constitutive relationship as follows:

$$
\begin{aligned}
& \sigma_{c}=\sigma_{u}\left[A \frac{\varepsilon}{\varepsilon_{0}}-B\left(\frac{\varepsilon}{\varepsilon_{0}}\right)^{2}\right] \quad \varepsilon \leq \varepsilon_{0} \\
& \sigma_{c}=\sigma_{u}(1-q)+\sigma_{u} q\left(\frac{\varepsilon}{\varepsilon_{0}}\right)^{(0.2-\alpha)} \quad \varepsilon>\varepsilon_{0}
\end{aligned}
$$

where 


$$
\begin{aligned}
\sigma_{u} & =f_{c k}\left[1+\left(\frac{30}{f_{c u}}\right)^{0.4}\left(-0.0626 \xi^{2}+0.4848 \xi\right)\right] \\
\varepsilon_{0} & =\varepsilon_{c}+3600 \sqrt{\alpha} \quad(\mu \varepsilon) \\
\varepsilon_{c} & =1300+10 f_{c u} \\
A & =2-K, \quad B=1-K \\
K & =\left(-5 \alpha^{2}+3 \alpha\right)\left(\frac{50-f_{c u}}{50}\right) \\
& +\left(-2 \alpha^{2}+2.15 \alpha\right)\left(\frac{f_{c u}-30}{50}\right) \\
q & =\frac{K}{0.2+\alpha}, \quad f_{c k}=0.8 f_{c u} \\
\xi & =\frac{\alpha f_{y}}{f_{c k}}, \quad \alpha=\frac{A_{s}}{A_{c}}
\end{aligned}
$$

And $\xi$ is the parameter about confining effect, which is equal to the ratio of compressive capacities of steel tube and concrete core. It is convenient for application and can be used for C30-C50. It can be seen that Young's modulus is not available in the formulation, and the relationship between standard strength $f_{c k}$ and cubic compressive strength $f_{c u}$ is different with the definition of national code either.

\section{MODEL OF LINHAI HAN}

Also based on the parameter of confining effect, professor Han developed his stress-strain relationship for concrete core through axial compression results of more than 400 short columns.

The parameter of confining effect is defined as:

$$
\xi=\frac{A_{s} f_{y}}{A_{c} f_{c k}}=\alpha \frac{f_{y}}{f_{c k}}
$$

and compression skeleton curve is defined as follows:

$$
\left\{\begin{array}{l}
\sigma_{c}=\sigma_{0}\left[A \frac{\varepsilon_{c}}{\varepsilon_{0}}-B\left(\frac{\varepsilon_{c}}{\varepsilon_{0}}\right)^{2}\right] \quad\left(\varepsilon_{c} \leq \varepsilon_{0}\right) \\
\sigma_{c}=\sigma_{0}(1-q)+\sigma_{0} q\left(\frac{\varepsilon_{c}}{\varepsilon_{0}}\right)^{0.1 \xi} \quad\left(\varepsilon_{c}>\varepsilon_{0}, \xi \geq 1.12\right) \\
\sigma_{c}=\frac{\sigma_{0}\left(\frac{\varepsilon_{c}}{\varepsilon_{0}}\right)}{\beta\left(\frac{\varepsilon_{c}}{\varepsilon_{0}}-1\right)^{2}+\frac{\varepsilon_{c}}{\varepsilon_{0}}} \quad\left(\varepsilon_{c}>\varepsilon_{0}, \xi<1.12\right)
\end{array}\right.
$$

where 


$$
\begin{aligned}
& \sigma_{0}=f_{c k}\left[1.194+\left(\frac{13}{f_{c k}}\right)^{0.45}\left(-0.07485 \xi^{2}+0.5789 \xi\right)\right] \\
& \varepsilon_{0}=\varepsilon_{c c}+\left[1400+\frac{800\left(f_{c k}-20\right)}{20}\right] \xi^{0.2} \quad(\mu \varepsilon) \\
& \varepsilon_{c c}=1300+14.93 f_{c k} \quad(\mu \varepsilon) \\
& A=2-k \quad B=1-k \quad k=0.1 \xi^{0.745} \\
& q=\frac{k}{0.2+0.1 \xi} \\
& \beta=\left(2.36 \times 10^{-5}\right)^{0.25+(\xi-0.5)^{7}} f_{c k}^{2} \times 5 \times 10^{-4}
\end{aligned}
$$

This model is applicable for C30-C90. The same with Zhong's model, it has no Young's modulus in formulation, and the characteristic value of compression strength for those concrete higher than $\mathrm{C} 40$ are all different with current national criteria.

\section{COMPARISON AND ANALYSIS}

Compression skeleton curves of these three models are compared firstly by using parameters of confining effect $\xi=0.5$ and $\xi=1.0$ for concrete filled steel tube, and $\mathrm{H}$ and $\mathrm{Z}$ are used to denote Han's and Zhong's model respectively. The results are shown in Fig.1 and Fig.2:

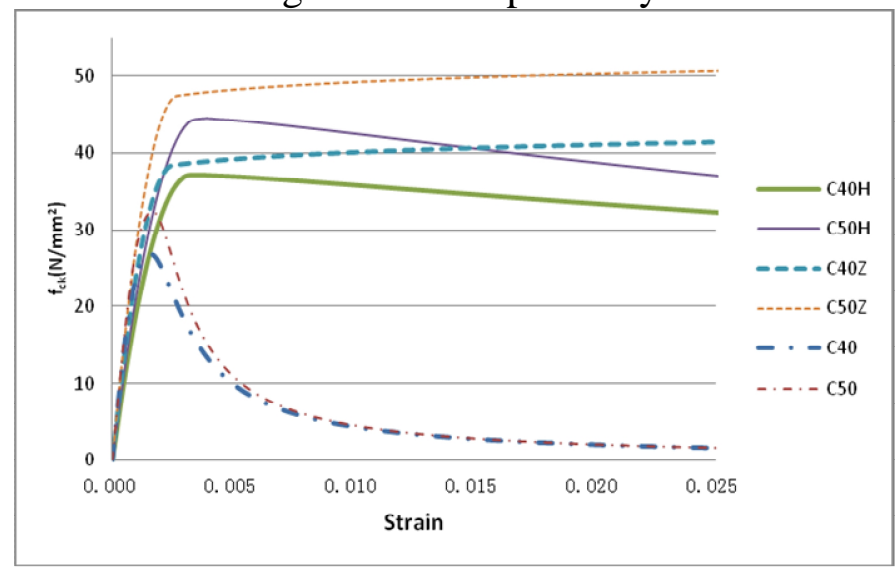

Fig.1 Compression skeletons $(\xi=0.5)$

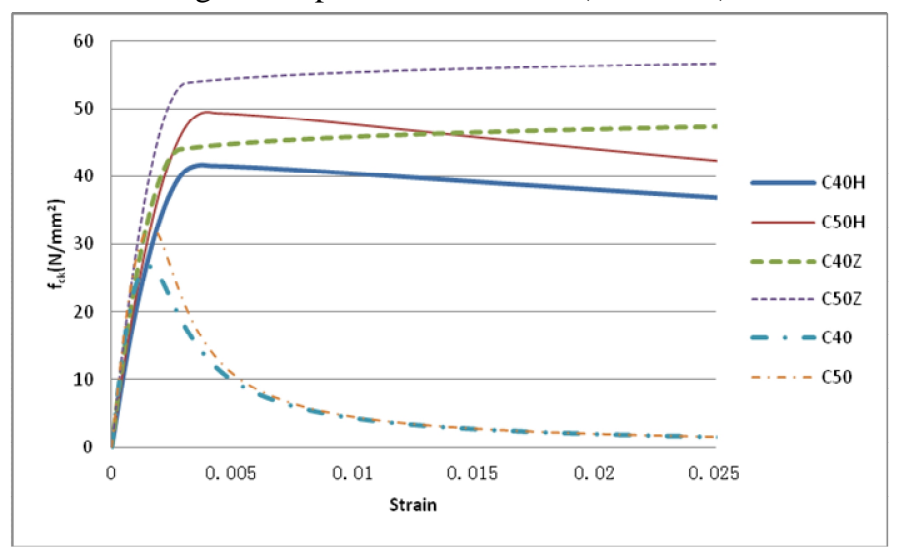

Fig.2 Compression skeletons ( $\xi=1.0$ )

As shown in Fig.1 and Fig2., strength of plain concretes formulated by national code degraded rapidly after the peak values. Under the confinement of steel tube, concrete core can exhibit much higher strength and ductility. The ultimate strength in Han's model increases about $35 \%$ and it in- 
creases even much more significant in Zhong's model; when $\xi<=1.0$, the strength in Han's model will still decrease more or less as $\varepsilon_{c}>\varepsilon_{0}$, but it will keep increasing in Zhong's model. Although both Han's model and Zhong's model can exhibit confinement effect of steel tube on concrete core, there are still significant differences between them.

As there is no Young's modulus from Eq.4 to Eq.8, it may affect the connection with linear elasticity, and what's more, modal analysis will also depend on the equivalent Young's modulus. For Code's model, when $\varepsilon \rightarrow 0$, the Young's modulus can be derived as:

$$
\begin{array}{ll}
E=32500 & C 40 \\
E=34500 & C 50
\end{array}
$$

But in Han's model:

if $\xi=0$ :

$$
\begin{array}{ll}
\sigma=0.03764 \varepsilon-1.107 \times 10^{-5} \varepsilon^{2} & C 40 \\
\sigma=0.04338 \varepsilon-1.216 \times 10^{-5} \varepsilon^{2} & C 50
\end{array}
$$

when $\varepsilon \rightarrow 0$ and $\xi=0$, the Young's modulus can be derived as:

$$
\begin{array}{ll}
E=37640 \mathrm{KN} / \mathrm{m}^{2} & C 40 \\
E=43380 \mathrm{KN} / \mathrm{m}^{2} & C 50
\end{array}
$$

if $\xi=0.5$ :

and if $\xi=1.0$ :

$$
\begin{array}{ll}
\sigma=0.02290 \varepsilon-3.516 \times 10^{-5} \varepsilon^{2} & C 40 \\
\sigma=0.02514 \varepsilon-3.548 \times 10^{-5} \varepsilon^{2} & C 50
\end{array}
$$

$$
\begin{array}{ll}
\sigma=0.02353 \varepsilon-3.305 \times 10^{-5} \varepsilon^{2} & C 40 \\
\sigma=0.02557 \varepsilon-3.291 \times 10^{-5} \varepsilon^{2} & C 50
\end{array}
$$

the relative Young's modulus also can be derived.

In Zhong's model

if $\xi=0$ :

$$
\begin{array}{ll}
\sigma=0.03765 \varepsilon-1.107 \times 10^{-5} \varepsilon^{2} & C 40 \\
\sigma=0.04444 \varepsilon-1.235 \times 10^{-5} \varepsilon^{2} & C 50
\end{array}
$$

when $\varepsilon \rightarrow 0$, and $\xi=0$, the Young's modulus can be derived as:

$$
\begin{array}{ll}
E=37650 \mathrm{KN} / \mathrm{m}^{2} & C 40 \\
E=44440 \mathrm{KN} / \mathrm{m}^{2} & C 50
\end{array}
$$

if $\xi=0.5$ :

$$
\begin{array}{ll}
\sigma=0.03039 \varepsilon-5.997 \times 10^{-5} \varepsilon^{2} & C 40 \\
\sigma=0.03471 \varepsilon-6.350 \times 10^{-5} \varepsilon^{2} & C 50
\end{array}
$$

if $\xi=1.0$ :

$$
\begin{array}{ll}
\sigma=0.03018 \varepsilon-5.162 \times 10^{-5} \varepsilon^{2} & C 40 \\
\sigma=0.03396 \varepsilon-5.350 \times 10^{-5} \varepsilon^{2} & C 50
\end{array}
$$

It can be seen that the equivalent Young's modulus of these two models will keep variable about $\xi$, then they cannot degenerated to elastic state even if $\xi=0$.

Thorough analysis are made for the initial stage of compression skeleton curves to reveal the reasons as shown in Fig.3 and Fig.4: 


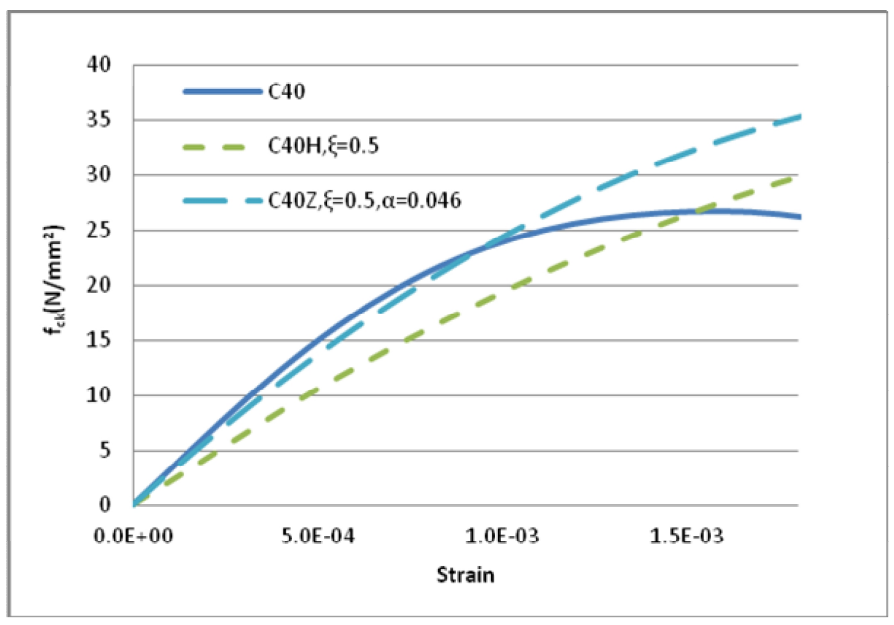

Fig.3 Initial stage of skeleton Curves for C40

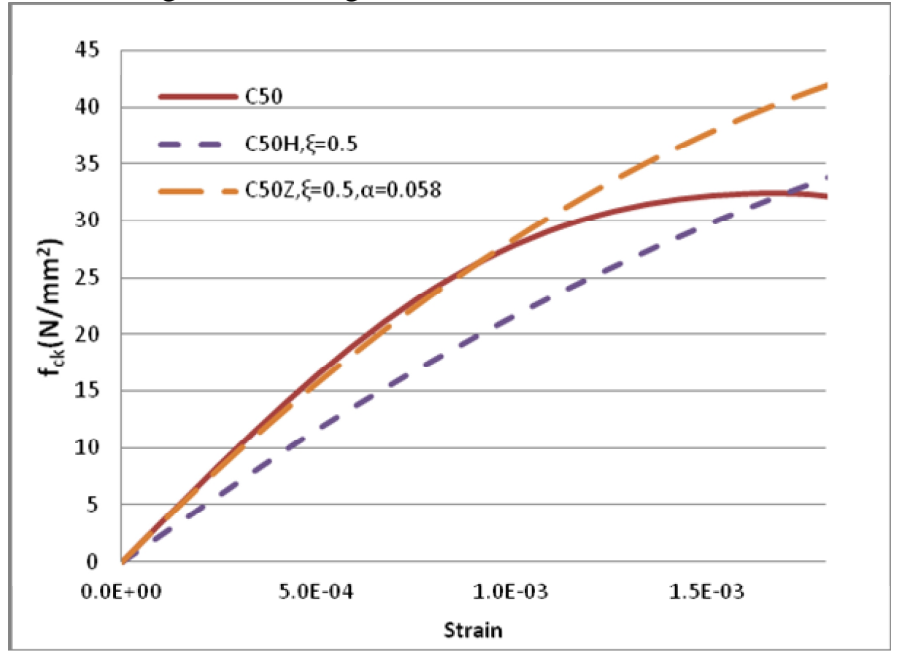

Fig.4 Initial stage of skeleton Curves for C50

Results show that the strength of concrete in Han's model and Zhong's model may be even lower than plain concrete presented in Code's model as the strain less than $1.0^{-3}$.

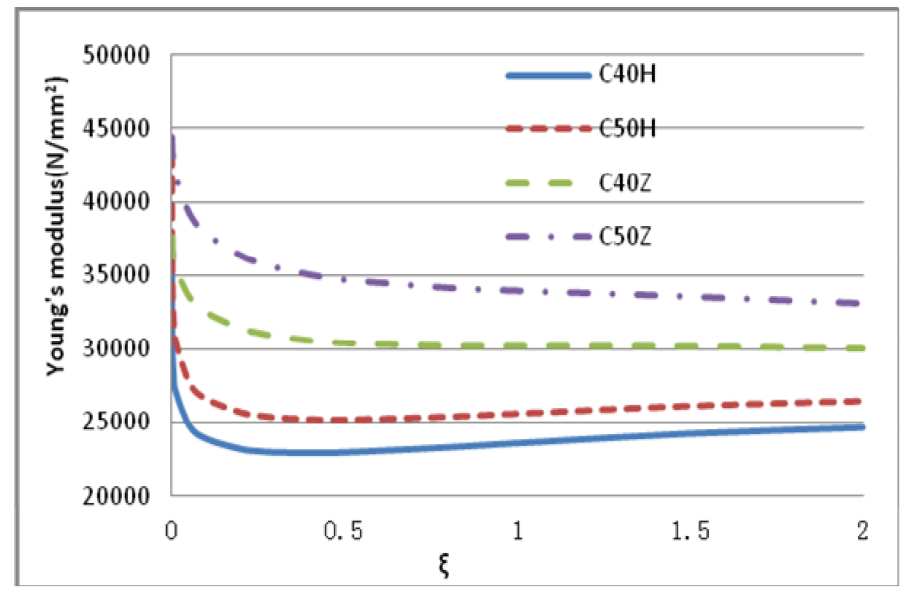

Fig.5 Equivalent Young's modulus in zero-stress state

Curves of equivalent Young's modulus also can be figured out about the parameter of $\xi$ as shown in Fig.5. It can be seen that equivalent Young's modulus only can keep steady as $\xi>0.5$, and it will varied severely if $\xi$ is out of this range.

\section{SUMMARY}

By the comparison between two kinds of constitutive relationship for concrete filled steel tube and a plain concrete presented by Chinese national code, the confinement effects of different models are 
researched for low-stress state as focus. The results show that these two models for concrete filled steel tube all can being used for simulating the action of steel tube on concrete core, but there are significant deviations for equivalent Young's modulus and initial stage of skeleton curves, with these deviations, the results of modes may not be very reliable and extra tolerance will be introduced to other cases of analysis too. On the other hand, the confinement effect of Zhong's model is much higher than Han's model, so it should be used carefully.

\section{Reference}

- China architecture \& building press(2011). Code for design of concrete structures, Beijing, China. (In Chinese).

- Ren Chongcui, Xu Ziguo, Tian Chunyu, et al.(2013) Application and analysis of steel plate concrete composite wall in outrigger trusses areas of Chow Tai Fook (Guangzhou) Center, Building Structures, Vol 16 . (In Chinese)

- Yuan Weibin, Jin Weiliang(2004). Studies on constitutive relationship for concrete filled steel tube. Journal of Zhejing university, 38(8):984-990. (In Chinese)

- Susantha K., Ge H, Usami T(2001). Uniaxial stress-strain relationship of concrete by various shaped steel tubes. Engineering Structures, 23(10):1331-1347.

- Hsuan-The Hu, M(2003).ASCE, Chiung-Shiann Huang, Ming-Hsien Wu. Nonlinear analysis axially loaded concrete-filled tube columns with confinement effect. Journal of Structural Engineering, 129(10): 1322-1329.

- Zhong Shantong(2003). The concrete-filled steel tubular structures. Tsinghua university press. Beijing. (In Chinese)

- Han Linhai(2007). Concrete-filled steel tube structure. Science press. Beijing. (In Chinese) 